Argonne, IL 60439

\title{
PROOF-OF-CONCEPT FLOWSHEET TESTS FOR CAUSTIC-SIDE SOLVENT EXTRACTION OF CESIUM FROM TANK WASTE
}

R. A. Leonard, S. B. Aase, H. A. Arafat, C. Conner, J. R. Falkenberg, and G. F. Vandegrift

Chemical Technology Division

November 2000 


\section{TABLE OF CONTENTS}

Page

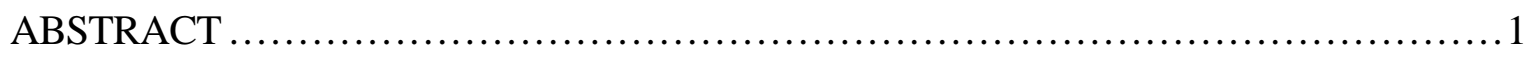

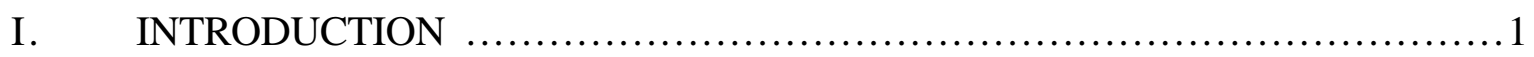

II. EQUIPMENT AND MATERIALS .........................................

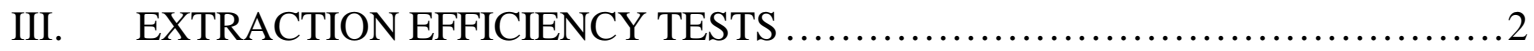

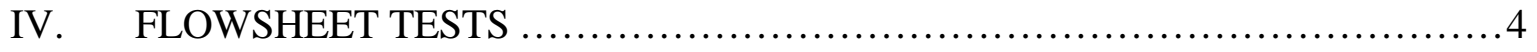

1. Without Solvent Recycle ............................................. 4

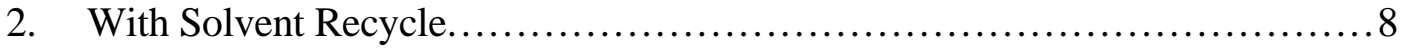

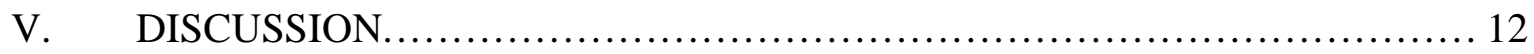

VI. SUMMARY AND CONCLUSIONS …................................... 16

ACKNOWLEDGMENTS ...................................................... 17

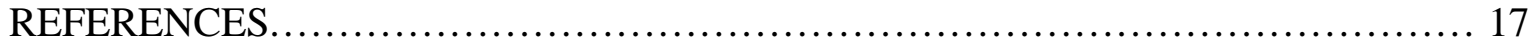




\section{LIST OF TABLES}

No.

$\underline{\text { Title }}$

Page

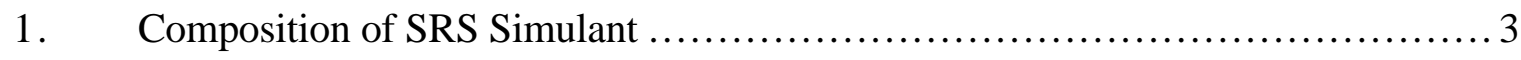

2. Stage Efficiency for Various Extraction Sections ............................. 4

3. Key Process Goals......................................................... 4

4. Changes in the Stripping, Decontamination, and Concentration Factors with

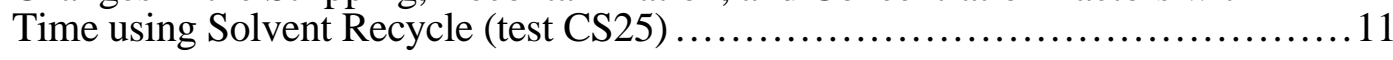

5. Final Effluent Concentrations for the CSSX Flowsheet Tests.....................12

6. Stage Efficiency for Flowsheet Tests ..................................... 16

\section{LIST OF FIGURES}

No. Title

1. CSSX Flowsheet for Test without Solvent Recycle (tests CS23 and CS24). Nominal flow rates are shown ...

2. Changes in the Stripping, Decontamination, and Concentration Factors with Time and Test CS23. The decrease in the decontamination factor with time was caused by the increase in the temperature of the aqueous (DW) raffinate 6

3. Changes in the Stripping, Decontamination, and Concentration Factors with Time for Test CS24. 9

4. CSSX Flowsheet for Test using Solvent Recycle (test CS25) 10

5. Changes in the Stripping, Decontamination, and Concentration Factors with Time using Solvent Recycle (test CS25)...

6. Stage-to-Stage Concentration Profile for Cesium at the End of the First Test with No Solvent Recycle (test CS23).

7. Stage-to-Stage Concentration Profile for Cesium at the End of the Second Test with No Solvent Recycle (test CS24)....

8. Stage-to-Stage Concentration Profile for Cesium at the End of the Test with Solvent Recycle (test CS25) 


\title{
PROOF-OF-CONCEPT FLOWSHEET TESTS FOR CAUSTIC-SIDE SOLVENT EXTRACTION OF CESIUM FROM TANK WASTE
}

\author{
by \\ R. A. Leonard, S. B. Aase, H. A. Arafat, C. Conner, J. R. Falkenberg, and G. F. Vandegrift
}

\begin{abstract}
A caustic-side solvent extraction (CSSX) process to remove cesium from Savannah River Site (SRS) high-level waste was tested in a minicontactor $(2-\mathrm{cm}$ centrifugal contactor). In the first phase of this effort, the minicontactor stage efficiency was improved from $60 \%$ to greater than $80 \%$ to meet the SRS process requirements using a 32-stage CSSX flowsheet. Then, the CSSX flowsheet was demonstrated in a 32-stage unit, first without solvent recycle, then with it. In both cases, the key process goals were achieved: (1) the cesium was removed from the waste with decontamination factors greater than 40,000 and (2) the recovered cesium was concentrated by a factor of 15 in dilute nitric acid. Oak Ridge National Laboratory (ORNL) analysis of the recycled solvent showed no evidence of impurity buildup.
\end{abstract}

\section{INTRODUCTION}

Savannah River Site (SRS) has 34 million gallons of high-level waste in 48 tanks that needs to be cleaned up [LEVENSON-2000]. As a part of the cleanup process, the cesium in this waste will be removed from a solution containing both supernate liquid and dissolved salt cake, then it will be vitrified for disposal. After the cesium is removed, the solution will be immobilized in low-level grout.

Work performed at Argonne National Laboratory (ANL) in FY1998 showed that cesium can be extracted from caustic aqueous solutions representative of the high-level waste at SRS using solvent extraction carried out in centrifugal contactors [LEONARD-1999, -2000]. The tests showed that, while the process worked, the solvent needed improvement, and the stage efficiency in the 2-cm centrifugal contactor was less than desired. The solvent was subsequently improved at Oak Ridge National Laboratory (ORNL) in FY1999 [BONNESEN-2000]. In the work reported here, the stage efficiency of the contactor was increased from 60 to $90 \%$. In addition, the number of contactor stages was increased from 24 to 32. Then, with the improved ORNL solvent and stage efficiency and the additional contactor stages, the process flowsheet required for removing cesium from high-level waste at SRS was demonstrated with a waste simulant.

This task is part of the integrated scope of work supporting the SRS High Level Waste Salt Processing Project (SPP). The work was performed in collaboration with Savannah River Technology Center (SRTC) and ORNL. Personnel at SRTC are performing tests with real waste, including batch solvent extraction and solvent irradiation. They are also planning for a flowsheet test with real waste in a 2 -cm centrifugal contactor. Personnel at ORNL are responsible for solvent development and commercialization. They are also evaluating the effect of heat and irradiation onthe solvent so that solvent cleanup methods can be developed. Finally, ORNL personnel are measuring stage efficiency in a larger $(5-\mathrm{cm})$ contactor to demonstrate that efficiency increases as the contactor size increases. The ANL work is a key part of the overall effort as it is the first proof- 
of-concept demonstration. In the overall SPP work, the caustic-side solvent extraction (CSSX) process is being compared with two alternative processes that also remove cesium from tank waste. These processes are (1) the tetraphenylborate (TPB) precipitation process, where TPB is used to precipitate out the cesium in small tanks, and (2) the crystalline silicotitanate (CST) ion exchange process, where CST is used to remove the cesium in packed beds [LEVENSON-2000]. Before the end of FY2001, one of these three processes will be chosen as the basis for the cesium removal component of a pant designed to treat all the SRS tank waste.

\section{EQUIPMENT AND MATERIALS}

The solvent extraction equipment for this task was an existing 24-stage 2-cm annular centrifugal contactor located in an ANL glovebox and an 8-stage 2-cm contactor set that was moved into the glovebox and connected to the 24-stage unit. The contactors, which are manufactured in banks of four stages, were built at ANL (see ANL print number CMT-E1265 entitled "2-cm Contactor" and dated 1/6/94). The 32 contactor stages were modified as discussed below to improve stage efficiency.

Highly alkaline simulant for tank supernate waste was prepared at ANL using a recipe supplied by SRS personnel [PETERSON-2000] and is designated "SRS simulant". Cesium-137 was added to the waste simulant at a concentration of $0.5 \mathrm{mCi} / \mathrm{L}$ to facilitate measurement of the cesium concentration. The scrub feed was $0.05 \underline{\mathrm{M} \mathrm{HNO}_{3}}$. The strip feed was $0.001 \underline{\mathrm{M}} \mathrm{HNO}_{3}$. Both acid feeds were prepared at ANL. The solvent, which was prepared at ORNL and shipped to ANL, consists of four components: (1) an extractant, a calixarene crown, calix[4]arene-bis(tertoctylbenzo-crown-6) designated BOBCalixC6, (2) a modifier, an alkyl aryl polyether, 1-(2,2,3,3,tetrafluoropropoxy)-3-(4-sec-butylphenoxy)-2-propanol, also called Cs-7SB, (3) a suppressant, an alkyl amine, trioctylamine (TOA), which suppresses impurity effects to ensure that the Cs can be stripped from the solvent, and (4) a diluent, a mixture of branched hydrocarbons, Isopar ${ }^{\circledR} \mathrm{L}$. The solvent composition is $0.01 \underline{\mathrm{M}}$ BOBCalixC6, $0.50 \underline{\mathrm{M}} \mathrm{Cs}-7 \mathrm{SB}$, and $0.001 \underline{\mathrm{M}}$ TOA in Isopar ${ }^{\circledR} \mathrm{L}$ and is designated the "CSSX solvent".

\section{EXTRACTION EFFICIENCY TESTS}

The stage efficiency needed to be improved from $60 \%$ seen earlier [LEONARD-1999] to greater than $80 \%$ in order to meet the SRS requirements for the CSSX flowsheet in the 32 contactor stages. Low stage efficiency had been attributed to slug flow in the interstage lines of the 2-cm contactor. Slug flow results when the inertial (i.e., pumping) forces of the liquid spun out of the rotor are dissipated before the liquid exits the contactor housing. This happens at the low flow rates needed for the $2-\mathrm{cm}$ contactor, that is, at less than $100 \mathrm{~mL} / \mathrm{min}$. In this low-flow regime, surface tension forces control the release of the liquid from the contactor housing and give rise to a slug or drip flow in the interstage line between stages as well as the exit ports. Based on these observations, three changes were made to improve stage efficiency in the 2-cm contactor. First, the inlet diameter of the 2 -cm rotor was enlarged from 7.92 to $10.72 \mathrm{~mm}(0.312$ to 0.422 inches) to retain more liquid in the annular mixing zone. Measurements showed that the liquid volume in the annular mixing zone was increased by 60 to $90 \%$. Second, a wire rope (304 SS, $1.6 \mathrm{~mm}$ [1/16"] dia, 7 strands with 7 wires in each strand) was threaded through each interstage line to wick the liquid around from stage to stage and eliminate slug flow. Measurements showed that, for the aqueous phase, the average volume of a slug dropped from 0.80 to $0.06 \mathrm{~mL}$. Third, the total throughput in the extraction section was increased $50 \%$ (from 40 to $60 \mathrm{~mL} / \mathrm{min}$ ) to ensure that the low aqueous flow rates in the stripping section remain above $2 \mathrm{~mL} / \mathrm{min}$. 
Table 1. Composition of SRS Simulant

\begin{tabular}{|c|c|c|c|}
\hline Component & Units & Concentration & Notes \\
\hline $\mathrm{Na}^{+}$ & $\mathrm{mol} / \mathrm{L}$ & 5.6 & \\
\hline $\mathrm{K}^{+}$ & " & 0.015 & \\
\hline $\mathrm{Cs}^{+}$ & “ & 0.00014 & $\mathrm{a}$ \\
\hline $\mathrm{OH}^{-}$ & “ & 2.06 & \\
\hline $\mathrm{NO}_{3}^{-}$ & " & 2.03 & \\
\hline $\mathrm{NO}_{2}^{-}$ & " & 0.50 & \\
\hline $\mathrm{AlO}_{2}^{-}$ & “ & 0.28 & \\
\hline $\mathrm{CO}_{3}^{2-}$ & “ & 0.15 & \\
\hline $\mathrm{SO}_{4}^{2-}$ & “" & 0.14 & \\
\hline $\mathrm{Cl}^{-}$ & “ & 0.024 & \\
\hline $\mathrm{F}^{-}$ & “ & 0.028 & \\
\hline $\mathrm{PO}_{4}^{3-}$ & “ & 0.007 & \\
\hline $\mathrm{C}_{2} \mathrm{O}_{4}^{2-}$ & " & 0.008 & \\
\hline $\mathrm{SiO}_{3}^{2-}$ & “ & 0.03 & \\
\hline $\mathrm{MoO}_{4}^{2-}$ & “ & 0.000078 & \\
\hline $\mathrm{NH}_{3}$ & " & 0.001 & \\
\hline Copper & $\mathrm{mg} / \mathrm{L}$ & 1.44 & \\
\hline Chromium & “ & 75 & \\
\hline Ruthenium & “" & 0.82 & \\
\hline Palladium & " & 0.41 & \\
\hline Rhodium & “ & 0.21 & \\
\hline Iron & “ & 1.44 & \\
\hline Zinc & “ & 8 & \\
\hline Tin & " & 2.4 & \\
\hline Mercury & " & 0.05 & \\
\hline Lead & “ & 2.1 & \\
\hline Silver & “" & 0.01 & \\
\hline Tri-n-butyl phosphate (TBP) & “ & 0.5 & \\
\hline Di-n-butyl phosphate (DBP) & “ & 25 & \\
\hline Mono-n-butyl phosphate (MBP) & " & 25 & \\
\hline n-Butanol & “" & 2 & \\
\hline Formate & “ & 1500 & \\
\hline Tri-methylamine & " & 10 & \\
\hline
\end{tabular}

${ }^{a} \mathrm{Cs}-137$ content of the average waste is $22.6 \%$. 
To evaluate these improvements, we conducted three extraction efficiency tests, corresponding to the extraction (4 stages), scrub (2 stages), and strip (4 stages) sections. Flow rates and feed compositions were very close to the values expected in the CSSX flowsheet tests. The results, given in Table 2, show that the modifications resulted in meeting the goal of stage efficiencies greater than $80 \%$. The average stage efficiency was $89.5 \pm 2.0 \%$. With the successful completion of these tests, the remaining contactor stages were modified, and the eight additional contactor stages were added to the 24-stage unit. Since the average stage efficiency is significantly greater than $80 \%$, not all of the eight additional contactor stages should be necessary. However, since stage efficiency can be lower if conditions are not right for the small centrifugal contactor, using all eight stages gives us some margin for error and helps ensure that we will be able to achieve the process goals during the flowsheet tests.

Table 2. Stage Efficiency for Various Extraction Sections

\begin{tabular}{|c|c|c|c|}
\hline Section & Stages & O/A & Efficiency, $\%$ \\
\hline Extraction & 4 & 0.31 & 92 \\
\hline Scrub & 2 & 5.4 & 89 \\
\hline Strip & 4 & 5.5 & 88 \\
\hline
\end{tabular}

${ }^{\mathrm{a} O r g a n i c-t o-a q u e o u s ~ f l o w ~ r a t i o . ~}$

\section{FLOWSHEET TESTS}

After the stage efficiency was improved and the additional contactor stages added, the CSSX flowsheet tests were carried out. The first two flowsheet tests were done without solvent recycle. The third test was done with solvent recycle. In each case, the results were compared to the key process goals given in Table 3 .

Table 3. Key Process Goals

\begin{tabular}{|c|c|}
\hline Operation & Goal \\
\hline Cs removal from tank waste (decontamination factor) & $>40,000$ \\
\hline Cs concentration in strip effluent (concentration factor) & $>12$ \\
\hline
\end{tabular}

\section{Without Solvent Recycle}

Two tests of the CSSX process CS23 and 24) were done without solvent recycle. The countercurrent solvent-extraction flowsheet for these tests, given in Fig. 1, has three sections (extraction, scrub, and strip). The extraction section is designed to remove Cs from the waste feed to the required level. In this section, the waste (DF) feed enters the process at stage 15, passes from stage 15 to 1 , then leaves at stage 1 as the decontaminated aqueous (DW) raffinate. At the same time, the solvent enters the extraction section at stage 1, moves from stage 1 to 15 , then enters the scrub section at stage 16 . Thus, the solvent takes a countercurrent path through the contactor relative to that of the waste feed. 


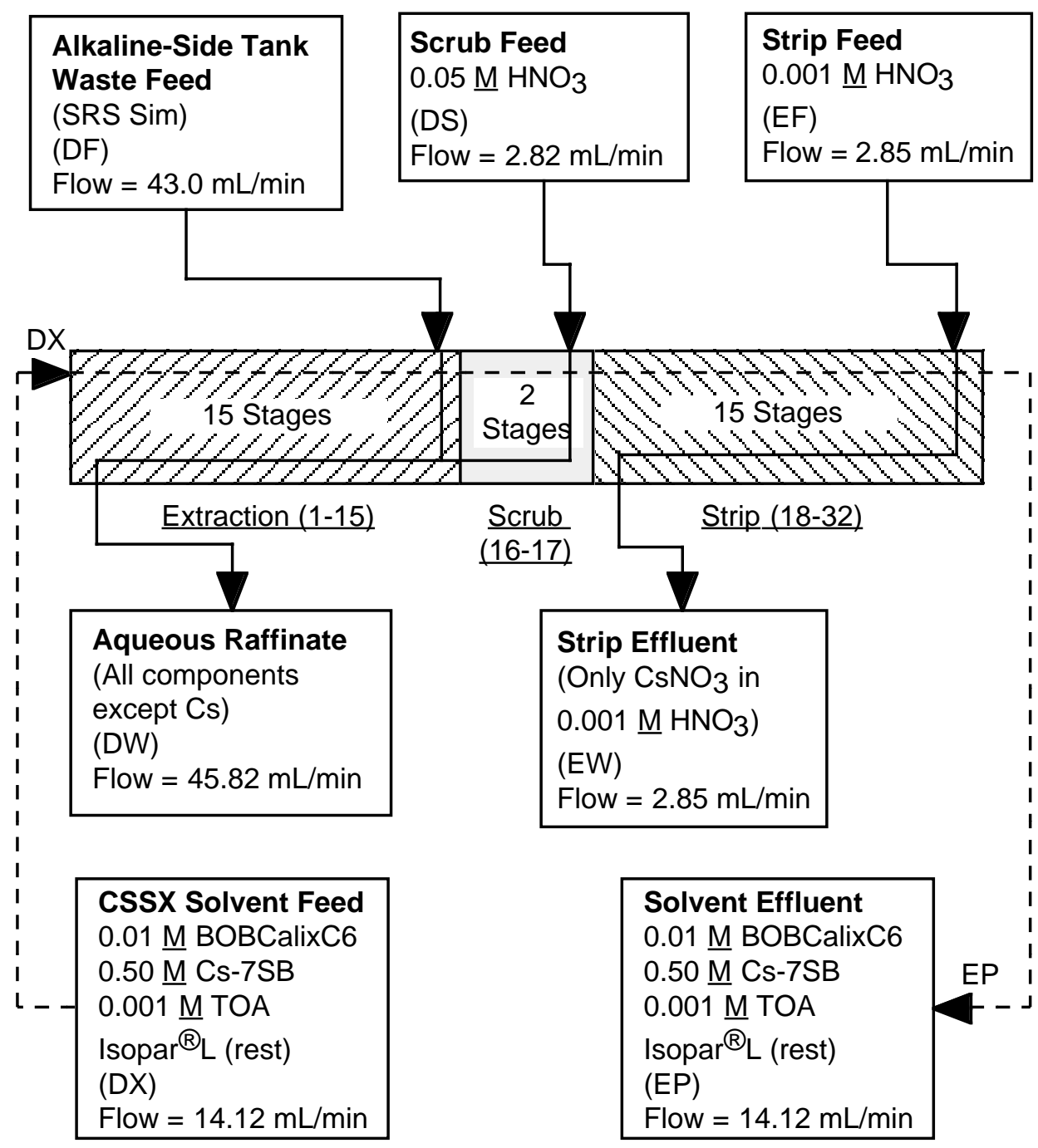

\section{Fig. 1. CSSX Flowsheet for Tests without Solvent Recycle (tests CS23 and CS24). Nominal flow rates are shown.}

The solvent was designed so that the distribution ratio ${ }^{1}$ of $\mathrm{Cs}$ is high in the extraction section; therefore, as the solvent passes from stage 1 to 15 , the organic-phase concentration of Cs increases. By the same mechanism, the concentration of $\mathrm{Cs}$ in the aqueous phase decreases as it passes from stage 15 to 1 . The effectiveness of the extraction section is defined by the decontamination factor, which is the Cs concentration in the waste feed entering stage 15 divided by that in the raffinate exiting stage 1. Figure 2 shows that the decontamination factor in test CS23 initially met the goal set in Table 3, then initially decreased with time. (As discussed below, a temperature rise in the extraction section caused this problem.)

\footnotetext{
${ }^{1}$ The distribution ratio is the organic concentration of a constituent divided by its aqueous concentration when the two liquids are in equilibrium. In the centrifugal contactor, each stage is an equilibration unit. When the distribution ratio of $\mathrm{Cs}\left(\mathrm{D}_{\mathrm{Cs}}\right)$ is greater than one, the organic-phase concentration of $\mathrm{Cs}$ is greater than its aqueousphase concentration when the two phases are equilibrated.
} 


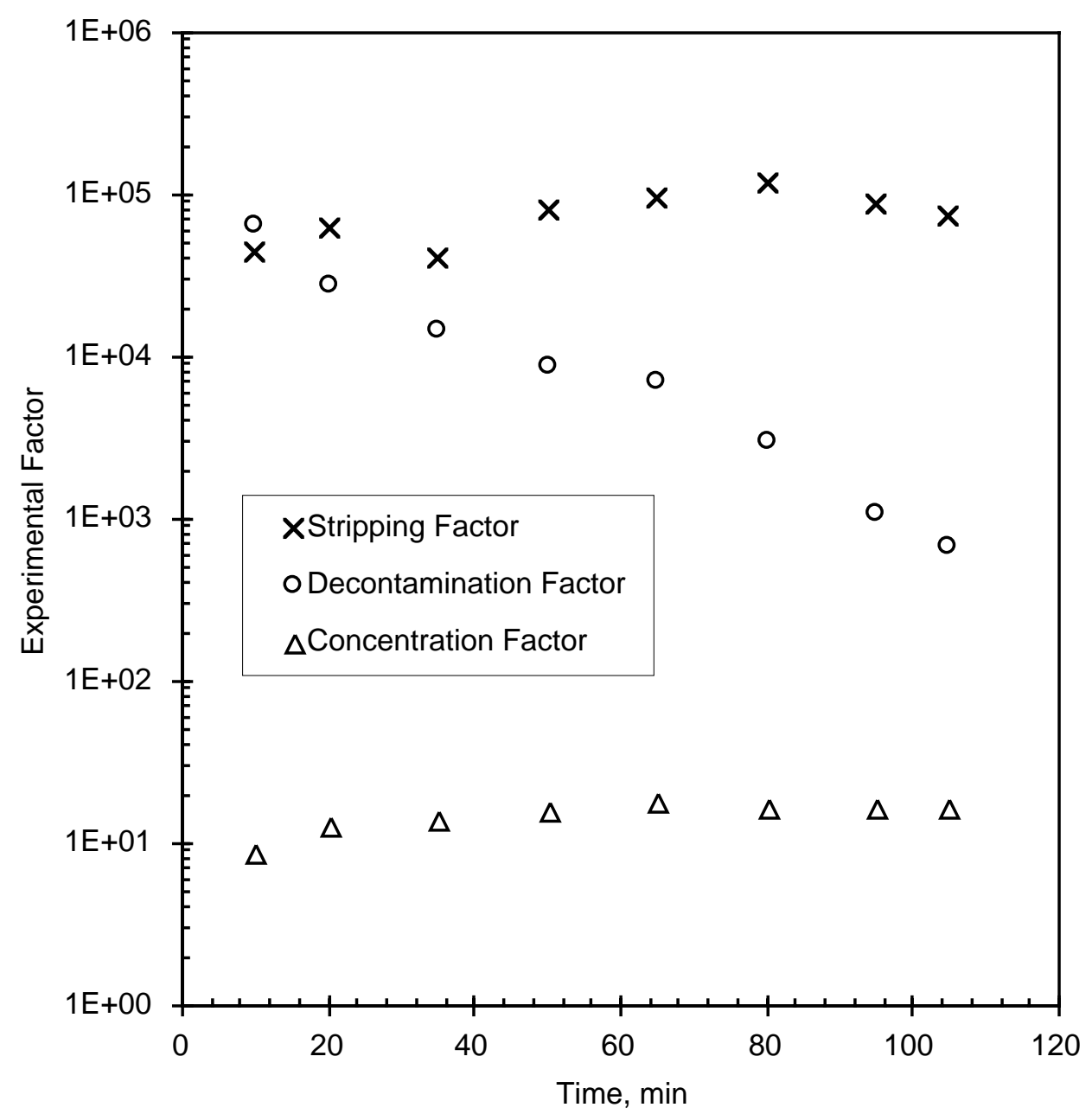

Fig. 2. Changes in the Stripping, Decontamination, and Concentration Factors with Time for Test CS23. The decrease in the decontamination factor with time was caused by the increase in the temperature of the aqueous (DW) raffinate.

The solvent leaving the extraction section is loaded with all the Cs that entered with the waste (DF) feed. The concentration of Cs in the solvent is that initially in the waste feed multiplied by the ratio of the waste (DF) feed flow rate divided by the solvent (DX) feed flow rate. Based on the flow rates in Fig. 1, the Cs is concentrated by a factor of 43/14.1 = 3.0 in the solvent.

The scrub section is designed to wash impurities from the solvent that are either carried as entrained aqueous phase or extracted into the solvent. The composition and flow rate of the aqueous scrub (DS) feed and the number of scrub stages required are set by the process requirements. In the CSSX process, extraction of impurities is minimal; therefore, only two scrub stages (16 and 17) are required. The aqueous scrub feed enters the scrub section at stage 17 and exits at stage 16 where it joins the waste feed going into stage 15 . The combined flow of the waste and the scrub feeds $(43.0+2.8=45.8 \mathrm{~mL} / \mathrm{min})$ exits the contactor at stage 1 as an aqueous (DW) raffinate. The solvent exits stage 17 still loaded with all the Cs that entered the process in the waste 7(DF) feed and flows into stage 18. 
Following scrubbing, the solvent passes through the strip section (stages 18-32), where the $\mathrm{Cs}$ is removed from the solvent into as aqueous strip solution. The composition of the aqueous strip (EF) feed is set to make the cesium distribution ratio low. The number of stages is set by the process goals in Table 1. The aqueous strip (EF) feed enters the contactor at stage 32 and flows to stage 18. At stage 18, the aqueous phase exits the contactor with all the Cs; this stream is designated the aqueous strip (EW) effluent. The solvent flows from stage 18 to 32, countercurrent to the aqueous strip phase. At stage 32, the solvent exits the contactor, free of Cs; this stream is designated the solvent (EP) effluent.

The effectiveness of the strip section is measured by the stripping factor, that is the ratio of the Cs concentration in the waste (DF) feed to that in the solvent (EP) effluent, or $[\mathrm{Cs}]_{\mathrm{DF}} /[\mathrm{Cs}]_{\mathrm{EP}}$. The higher the stripping factor, the cleaner the solvent exiting the process. As shown in Fig. 2 for test CS23, the stripping factor did not change much with time and always stayed above 40,000. As the Cs concentration of the solvent decreased while it moved from stage 18 to 32 in the strip section, the Cs concentration in the aqueous strip solution increased while it moved in the countercurrent direction, that is, from stage 32 to 18 . The aqueous strip (EW) effluent that leaves stage 18 contains all the Cs that entered with the waste (DF) feed. The Cs concentration in the aqueous strip (EW) effluent is the initial Cs concentration in the waste (DF) feed multiplied by the flow rate ratio of DF/EW, also known as the concentration factor. Based on the flowsheet in Fig. 1 , the concentration factor is $43 / 2.85=15.1$.

Figure 2 shows that the concentration factor for test CS23 increased steadily up to a steadystate value in about 30 minutes. This buildup in the cesium concentration is controlled by the rate at which cesium is carried into the contactor by the aqueous (DF) feed. After steady state, the small fluctuations in the cesium in the aqueous strip (EW) effluent reflects flow variations in the aqueous strip (EF) feed, as well as any changes in liquid inventory in the stages near stage 18, where the aqueous strip (EW) effluent exits.

The first flowsheet test (CS23) ran well early in this two-hour test. The strip section achieved the low Cs concentrations in the solvent (EP) effluent required for solvent recycle. The Cs was concentrated in the aqueous (EW) strip effluent by a factor of 16, meeting this process goal (Table 3). The Cs in the simulated SRS waste (DF) feed was removed from the aqueous (DW) raffinate with a decontamination factor of 66,000 after $10 \mathrm{~min}$, meeting this process goal (Table 3). While the Cs concentration in the solvent (EP) effluent stayed low and the aqueous strip (EW) effluent stayed high during the two-hour test, the Cs concentration in the aqueous (DW) raffinate concentration climbed with time. By the end of the test, it was only 680 times less than that of the waste (DF) feed. Figure 2 shows this decline in decontamination factor.

The decrease in the decontamination factor with time was attributed to a rise in the temperature in the extraction section. Earlier tests [BONNESEN-2000] showed that, as the temperature rises, the distribution ratio for cesium in the extraction section will decrease, resulting in less cesium removal. The rise in the temperature of the extraction section was detected by measuring the aqueous (DW) raffinate temperature. This temperature rose steadily from 32 to $37^{\circ} \mathrm{C}$ over the two-hour test. Analyses and tests done after test CS23 identified the heat from the rotor motors as the main source of this temperature rise. In these tests the temperature of the contactor body leveled off at a slightly lower temperature, that is, at 34 to $35^{\circ} \mathrm{C}$, after 2 to 3 hours. The fact that the motors were on an hour before the flow of waste feed was started may have contributed to the additional temperature rise. In addition, before the start of this test, the laboratory temperature had been increased from 18 to $25^{\circ} \mathrm{C}$ to ensure that the strip section would be at $25^{\circ} \mathrm{C}$. Earlier tests [BONNESEN-2000] showed that, as the temperature rises, the distribution ratio for cesium in the strip section will decrease, resulting in more cesium removal. A temperature of at least $25^{\circ} \mathrm{C}$ is desired to ensure that all strip stages work well, that is, that the $\mathrm{Cs}$ distribution ratio is $<0.2$. Since the O/A flow ratio is 5 in the strip section, Cs distribution ratios $>0.2$ will restrict the movement of the Cs through the strip section, and so, prevent the required stripping of the Cs from the solvent 
from occurring. Because of the motor heat, the temperature of the both strip effluents was significantly higher than $25^{\circ} \mathrm{C}$, leveling off at $32 \pm 1^{\circ} \mathrm{C}$. The high temperature in the strip section kept the stripping factor high throughout test CS23.

After test CS23, a heat balance showed that motor heat (12 W per stage) was the main reason that the temperature in the 2 -cm contactor stages increased above ambient temperature. In the larger contactors needed for a plant-scale process, the amount of motor heat relative to the flowing liquid would be less, and thus, so would the effect of motor heat. Based on the contribution of motor heat to the temperature in the 2-cm contactor stages, the temperature management plan was changed for test CS24. In particular, the motor heat was used to help keep the strip section at $25^{\circ} \mathrm{C}$ or above, while the extraction section was cooled to help offset the effect of motor heat. This was done by (1) cooling the laboratory from 25 to $18^{\circ} \mathrm{C}$, (2) cooling the simulant (DF) feed to the contactor in an ice bath, (3) not turning on the rotors in the extraction section until they were needed, and (4) turning on the rotors in the scrub and strip sections one hour before the test. Motor/rotor assemblies were replaced in several strip stages where the backup of liquid in the interstage lines was significantly higher than for the other stages. With these changes, test CS23 was repeated as test CS24. As shown in Fig. 3, this second CSSX flowsheet test without solvent recycle worked well over the entire two-hour test period. The concentration factor quickly increased to $16.0 \pm 0.9$. The stripping factor was high throughout the test, with an average value of 74,000 $\pm 13,000$ after the first five minutes. The decontamination factor was also high throughout the test, with an average value of 69,000 $\pm 14,000$ after the first five minutes. The temperature of the aqueous (DW) raffinate never exceeded $32^{\circ} \mathrm{C}$ (the highest temperature that still gave a decontamination factor $>40,000$ in test CS23), rising from 22 to $29^{\circ} \mathrm{C}$.

Thus, test CS24 met both process goals, that is, a decontamination factor $>40,000$ and a concentration factor $>12$. The results also showed that the process reached steady state in $20 \mathrm{~min}$ and continued to work well for the rest of the 100-min test. Owing to the success of this test, a decision was made to proceed with solvent recycle.

\section{With Solvent Recycle}

The CSSX flowsheet with solvent recycle (test CS25) was very similar to that for test CS24 (see Fig. 4). The difference is that the solvent was recycled four times. To achieve this recycle, the test lasted three hours. Action taken to correct hydraulic problems in the period between 25 and 50 min caused a dip in the decontamination and stripping factors. After this time the process stabilized at a concentration factor of $14.6 \pm 1.1$, a decontamination factor of 82,000 \pm 17,000, and a stripping factor of $117,000 \pm 20,000$. The results, given in Fig. 5 and Table 4, show that, from $65 \mathrm{~min}$ on, the process operated well above the test target of $>40,000$ for the decontamination factor. The concentration factor exceeded the test target of $>12$ after $20 \mathrm{~min}$. The variations in the measured concentration factor reflect the expected variations in process flow rates. In particular, since the Cs cannot leave in either the aqueous (DW) raffinate or the strip (EP) effluent, the concentration factor is essentially the waste (DF) feed rate divided by the strip (EF) feed rate. The stripping factor was obviously adequate for the solvent to be recycled. It kept the cesium concentration in the recycled solvent low and allowed the extraction section to perform well. Our temperature management plan was also successful; the aqueous (DW) raffinate never exceeded $32^{\circ} \mathrm{C}$. It started at $23^{\circ} \mathrm{C}$ and rose to $31^{\circ} \mathrm{C}$, where it stayed for the last $30 \mathrm{~min}$ of testing. 


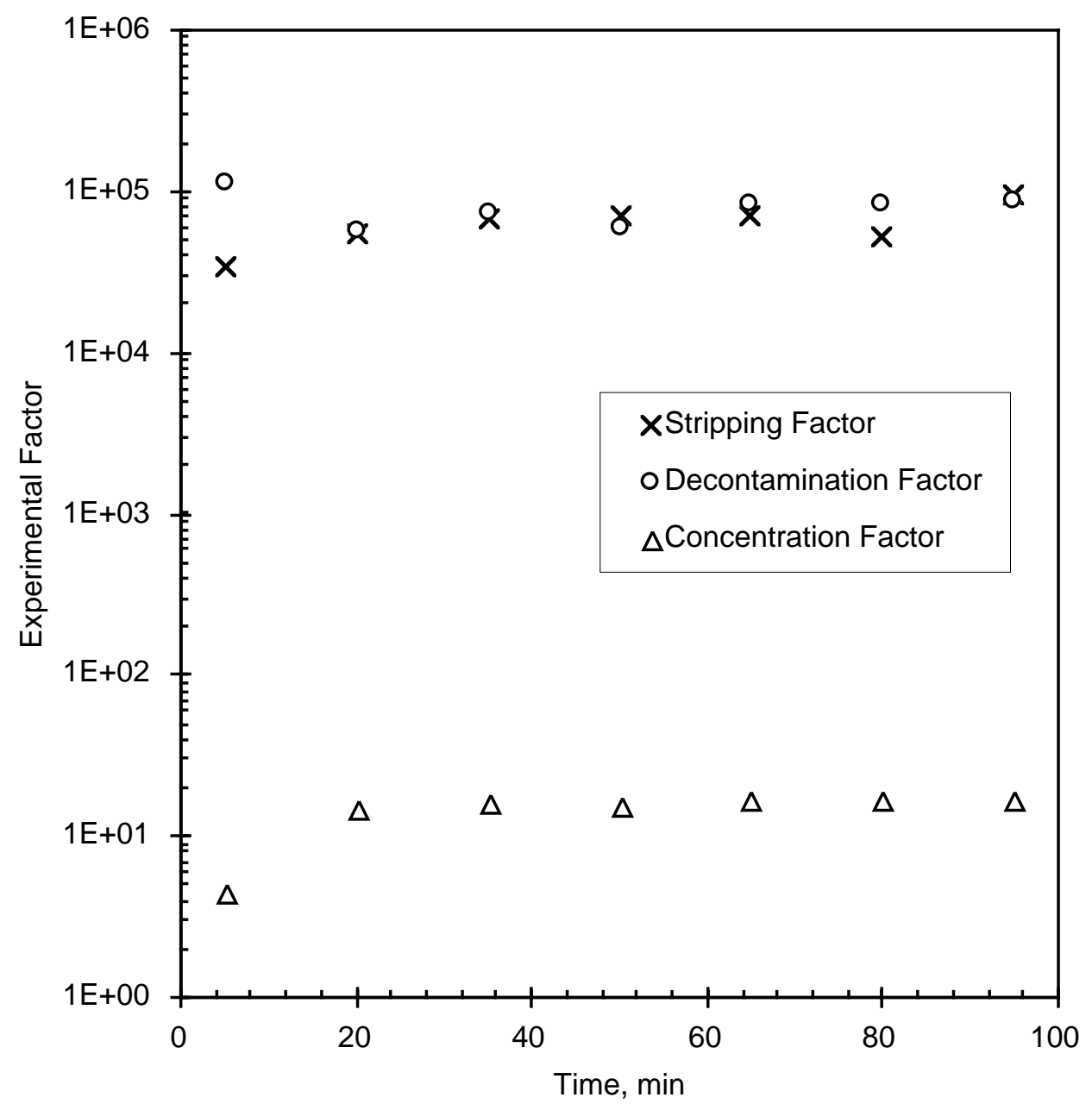

Fig. 3. Changes in the Stripping, Decontamination, and Concentration Factors with Time for Test CS24 


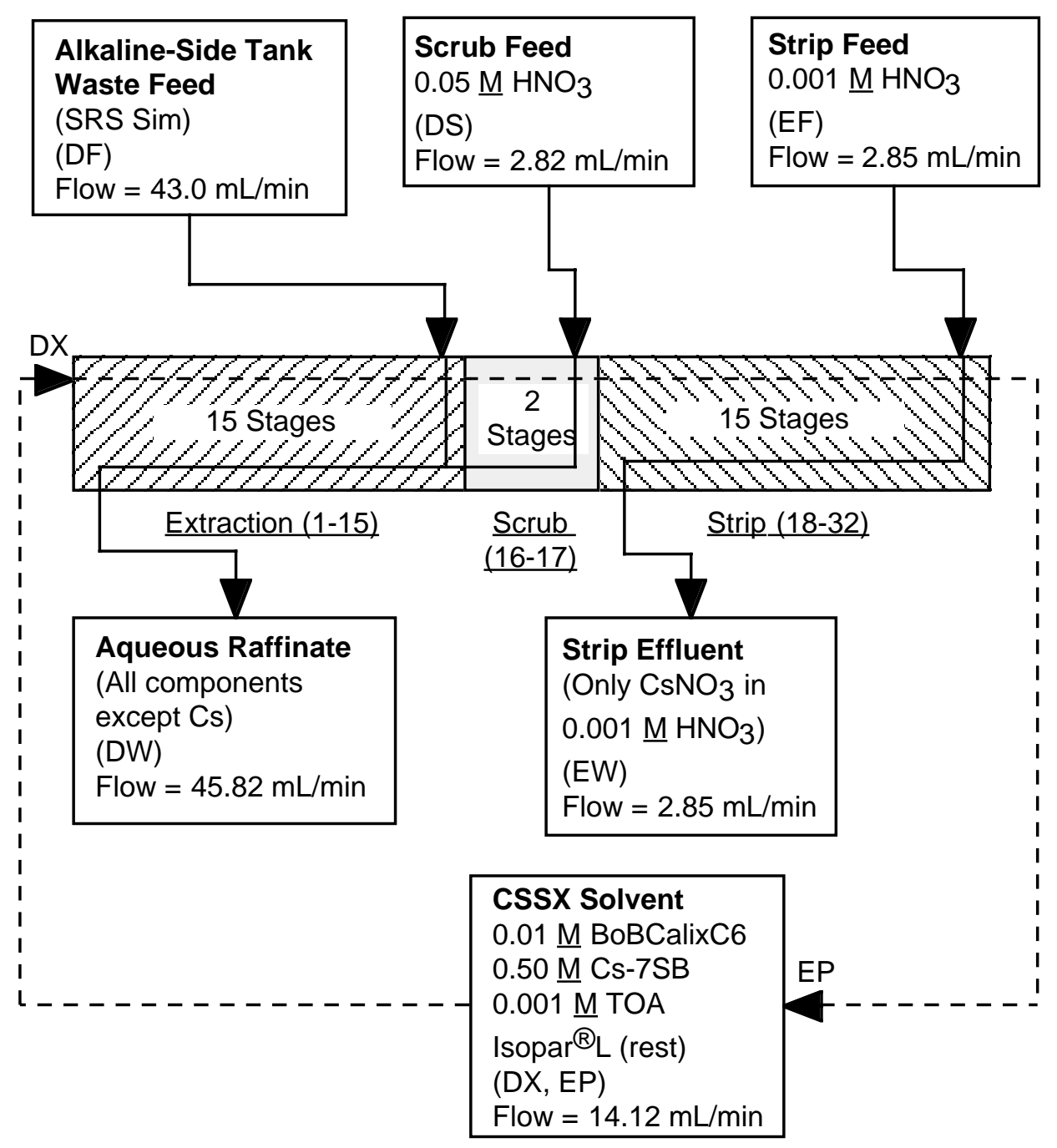

Fig. 4. CSSX Flowsheet for Test using Solvent Recycle (test CS25) 


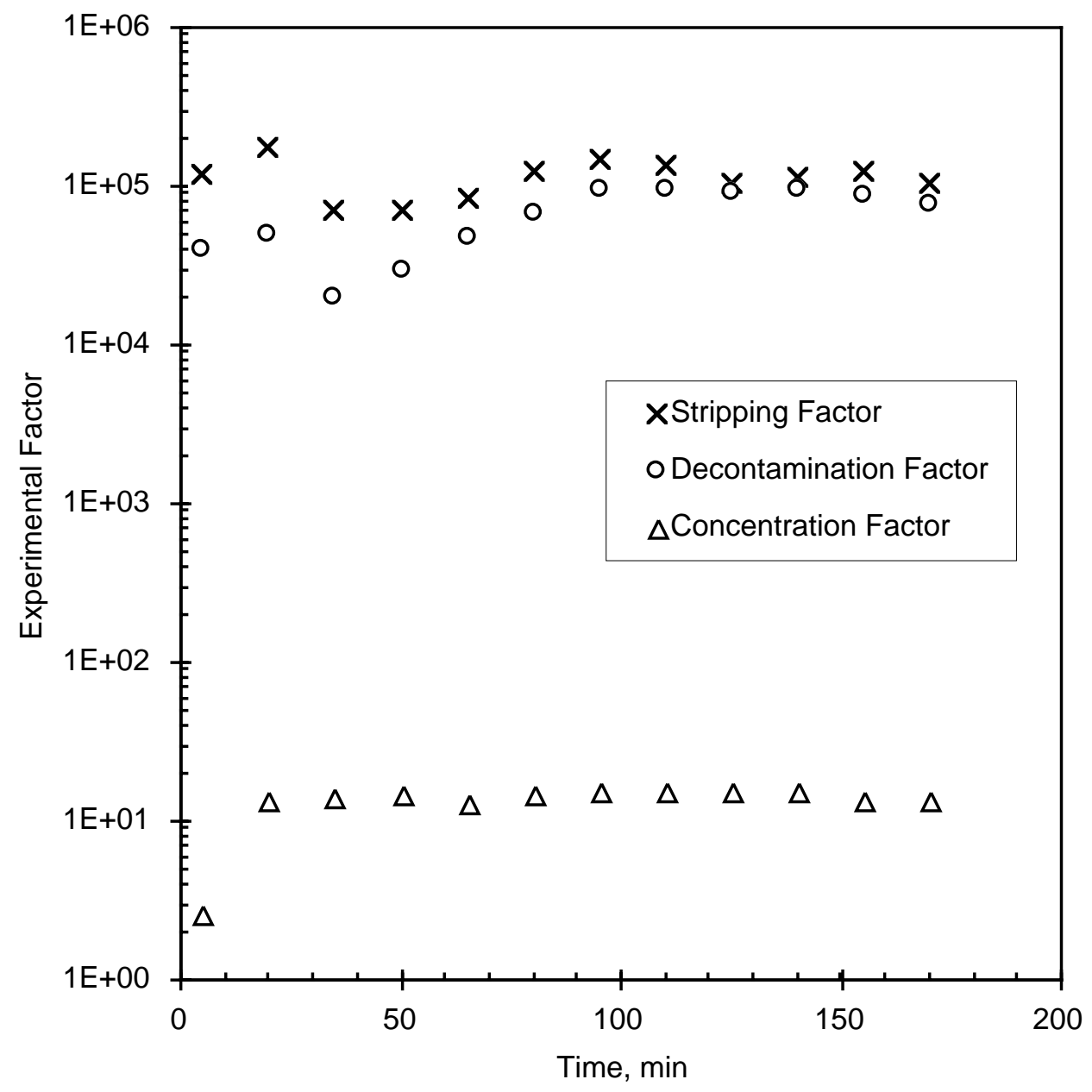

Fig. 5. Changes in the Stripping, Decontamination, and Concentration Factors with Time using Solvent Recycle (test CS25)

Table 4. Results from Flowsheet Test using Solvent Recycle (test CS25)

\begin{tabular}{|c|c|c|c|}
\hline Time, $\min$ & $\begin{array}{c}\text { Decontamination Factor for } \\
\text { Cesium, [DF]/[DW] }\end{array}$ & $\begin{array}{c}\text { Concentration Factor for } \\
\text { Cesium, [EW]/[DF] }\end{array}$ & $\begin{array}{c}\text { Stripping Factor for } \\
\text { Cesium, [DF]/[EP] }\end{array}$ \\
\hline 5 & 39,000 & 2.6 & 120,000 \\
\hline 20 & 49,000 & 13.5 & 172,000 \\
\hline 35 & 20,000 & 14.3 & 71,000 \\
\hline 50 & 29,000 & 14.7 & 70,000 \\
\hline 65 & 47,000 & 12.9 & 84,000 \\
\hline 80 & 67,000 & 15.0 & 124,000 \\
\hline 95 & 95,000 & 15.4 & 146,000 \\
\hline 110 & 97,000 & 15.7 & 136,000 \\
\hline 125 & 90,000 & 15.1 & 104,000 \\
\hline 140 & 94,000 & 15.8 & 113,000 \\
\hline 155 & 87,000 & 13.5 & 125,000 \\
\hline 170 & 78,000 & 13.8 & 104,000 \\
\hline
\end{tabular}


Thus, test CS25 met both process goals, that is, a decontamination factor $>40,000$ and a concentration factor $>12$, while recycling the solvent. Solvent recycle did not degrade process performance, at least for recycle of four times. Oak Ridge personnel tested the recycled solvent from test CS25 and found that it performed the same as virgin solvent. There was no evidence of impurity buildup. Thus, the highly alkaline character of the extraction section provides selfpurging of impurities that ORNL had found to build up after four solvent recycles using simple batch tests with only one extraction stage, one scrub stage, and several strip stages. Information gained from test CS25 will be used in preparing for the planned multi-day CSSX flowsheet tests at SRS and ANL. A key feature will be further improvements in the temperature management plan so that the effluent from the extraction section does not come so close to exceeding $32^{\circ} \mathrm{C}$, the highest temperature that still gave a decontamination factor $>40,000$ in test CS23.

\section{DISCUSSION}

Final effluent concentrations, given in Table 5, show that, except as noted, the aqueous (DW) raffinate and the organic (EP) effluent have about the same low concentration for both the once-through and the solvent-recycle tests. Why these effluents have about the same final Cs concentration is not understood. Several explanations are being considered. For example, it may be that residual Cs-137 contamination in the contactor becomes important at these low concentrations. Since the Cs concentration was about $1 \times 10^{-9} \underline{\mathrm{M}}$, the concentration of the Cs-137 isotope actually being measured was $3.4 \times 10^{-13} \mathrm{M}$. A second explanation is that the Cs can no longer be extracted or stripped because the solvent has reached its lower limit of operation, that is, some impurity in the solvent prevents further Cs extraction or stripping. However, the ability of Cs to be extracted from the aqueous phase in stage 1 and the ability of the Cs to be stripped from the solvent in stage 32 do not seem diminished at these low Cs concentrations.

Table 5. Final Effluent Concentrations for the CSSX Flowsheet Tests

\begin{tabular}{|c|c|c|c|c|}
\hline Test & $\begin{array}{c}\text { [Cs] in Aqueous } \\
\text { (DW) Raffinate, } \underline{\mathrm{M}}\end{array}$ & $\begin{array}{c}\text { [Cs] in Aqueous } \\
\text { Strip (EW) } \\
\text { Effluent, } \underline{M}\end{array}$ & $\begin{array}{c}\text { [Cs] in Organic } \\
\text { (EP) Effluent, } \underline{\mathrm{M}}\end{array}$ & Notes \\
\hline CS23 & $2.1 \mathrm{E}-09$ & $2.3 \mathrm{E}-03$ & $1.8 \mathrm{E}-09$ & $\mathrm{a}$ \\
\hline CS24 & $1.6 \mathrm{E}-09$ & $2.3 \mathrm{E}-03$ & $1.5 \mathrm{E}-09$ & \\
\hline CS25 & $1.8 \mathrm{E}-09$ & $1.9 \mathrm{E}-03$ & $1.4 \mathrm{E}-09$ & \\
\hline
\end{tabular}

a. The concentration of cesium in the aqueous (DW) raffinate is the value at 5 minutes into test CS23. As the temperature of the aqueous (DW) raffinate increased, this concentration also increased.

Cesium concentration profiles obtained at the end of tests CS23, CS24, and CS25 were reviewed in an effort to understand why the same low concentrations were obtained for both the once-through and the solvent-recycle tests. The Cs concentrations in these profiles were obtained by draining each contactor stage at the end of the test, equilibrating the two phases, taking samples of each phase, and measuring the Cs concentration in each phase. The temperature at equilibration was noted but not controlled. In addition, when the pump and rotor motors are shut down, liquid flow from stage to stage varies depending on how fast each pump and rotor slows down and stops after the power is cut off. Thus, the numbers given by these concentration profiles represent an approximation to the actual Cs concentration and can only be used to identify general trends. The Cs concentrations in the effluents, which are taken while the contactor is operating without interfering with its operation, do not have these problems and so are quite accurate. They allow 
one to get some idea of how the liquid drained from the stages and equilibrated differs from the actual concentration of that phase in that stage.

The Cs concentration results for both the stage and effluent samples are given in Figs. 6-8. They show that the high Cs concentrations initially dropped off sharply in both the extraction and strip sections. Then, as the final low concentrations given in Table 5 are approached, the concentration profiles in Figs. 6-8 flatten out. The last 4 to 8 stages of the extraction and strip sections do not contribute much to the total separation. The one exception is the extraction section at the end of test CS23. In this case, because the temperature was high, the distribution ratios for cesium were lower. As a result, the final cesium concentration in the extraction effluent for test CS23 did not reach the low values required for the CSSX process. This problem was resolved in tests CS24 and CS25 by using a revised temperature management plan. The Cs concentration profiles in Figs. 6-8 confirm that, except for the extraction section in test CS23 (stages 1-15) the stage-to-stage separation for Cs falls off as the low Cs concentrations given in Table 5 are reached. It does not give an explanation for this behavior. Further tests will be done in FY2001 to better understand this behavior.

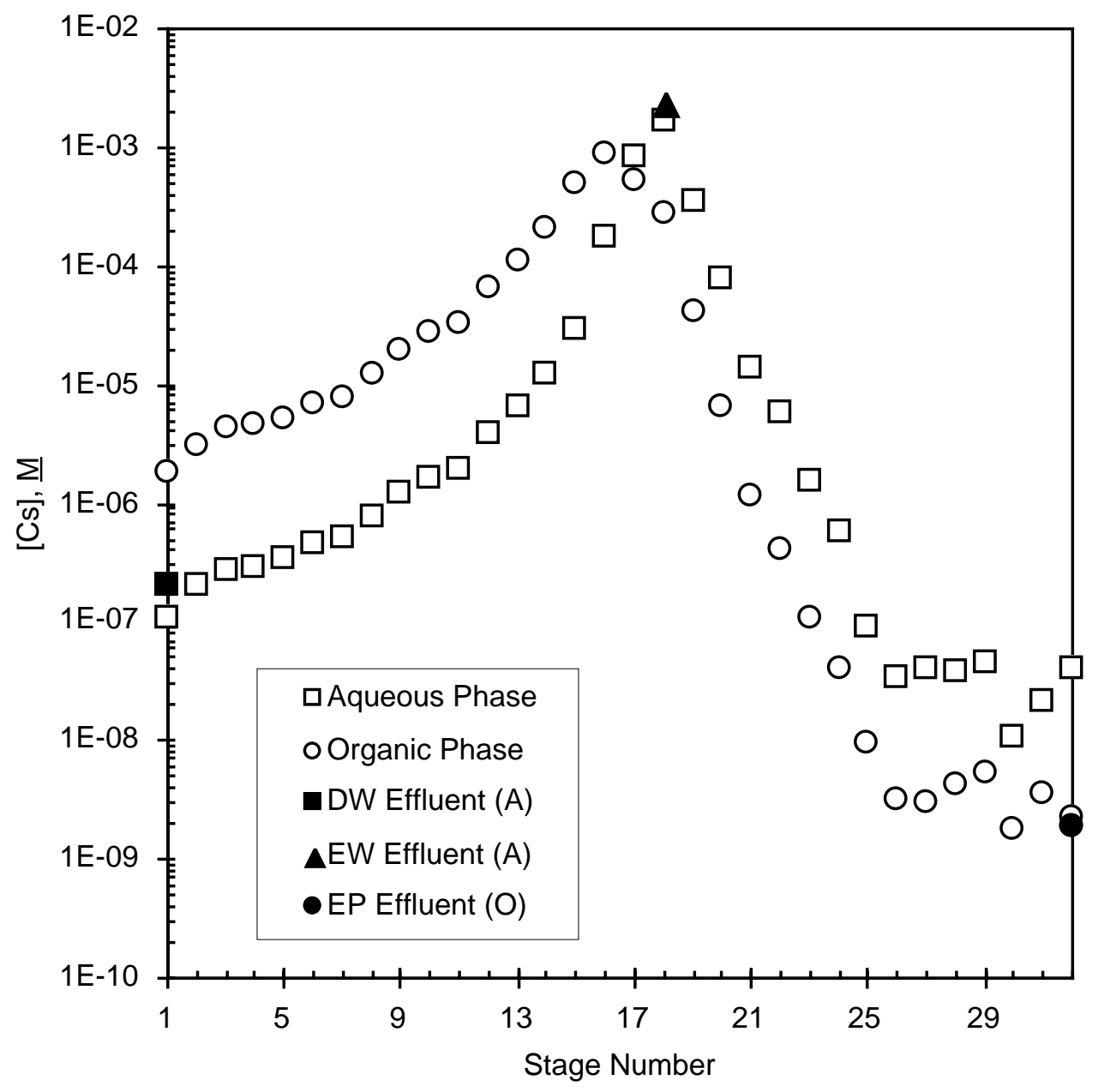

Fig. 6. Stage-to-Stage Concentration Profile for Cesium at the End of the First Test with No Solvent Recycle (test CS23) 


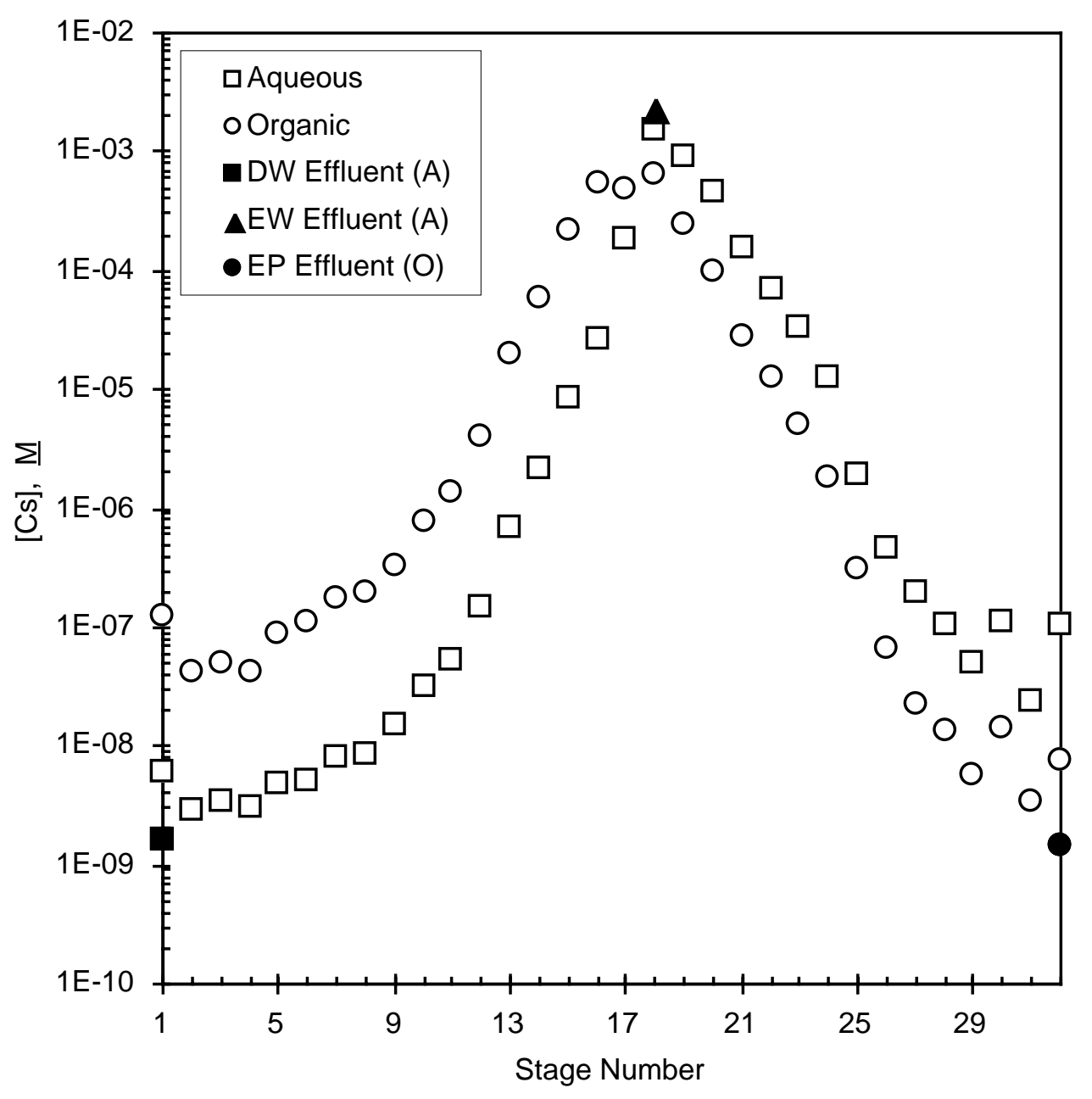

Fig. 7. Stage-to-Stage Concentration Profile for Cesium at the End of the Second Test with No Solvent Recycle (test CS24)

Applying the spreadsheet algorithm for stagewise solvent extraction (SASSE) [LEONARD1994] to the stage-to-stage concentration profiles for the flowsheet tests, we calculated the stage efficiencies for the extraction and strip sections. The results, given in Table 6, show that the improved stage efficiencies in the four-stage tests reported in Table 2 were also achieved in the flowsheet tests. In plant-scale annular centrifugal contactors, higher stage efficiencies are expected. For contactors with rotor diameters from 9 to $25 \mathrm{~cm}$, stage efficiencies are greater than 95\% [LEONARD-1999]. The CSSX process for the SRS tank waste would require a 25-cm contactor. 


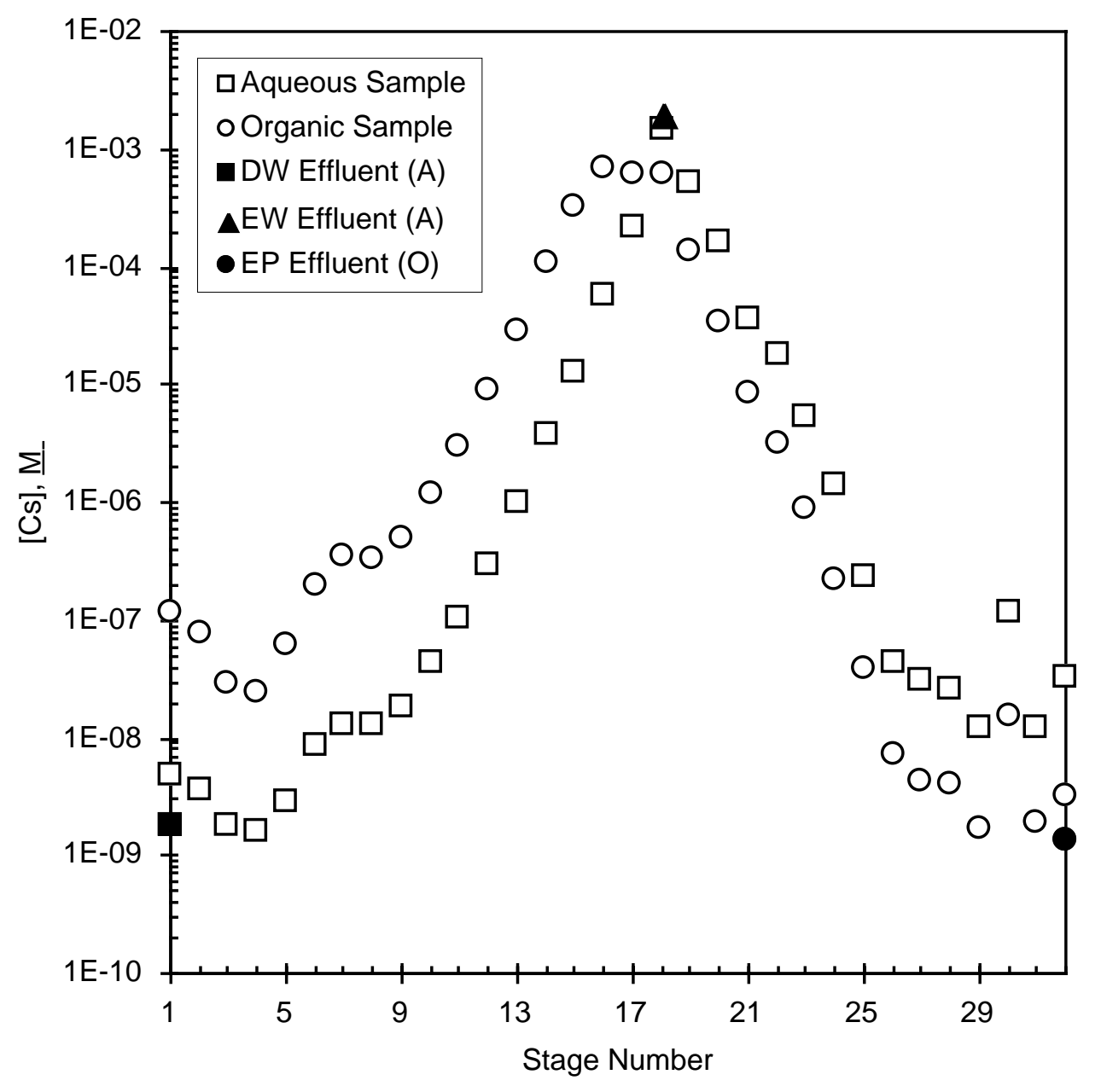
Fig. 8. Stage-to-Stage Concentration Profile for Cesium at the End of the Test
with Solvent Recycle (test CS25)

In the tests described here, good process operation was achieved by an appropriate temperature management plan. Another technique that can be used in place of, or in conjunction with, the temperature management plan is to vary the solvent flow rate while the aqueous (DF) and strip (EF) flow rates are held constant. This is possible since the cesium distribution ratios for both the extraction and strip sections decrease as the temperature increases. Thus, as temperature increases, the solvent flow rate could be increased to counteract the effect of the temperature rise. This would increase the organic-to-aqueous (O/A) flow ratio in the extraction section and, so, offset the drop in the cesium distribution ratio. This increase would also increase the O/A flow ratio in the strip section, which would impede strip section operation. However, the higher O/A flow ratio would be offset by the decreased cesium distribution ratio. In plant-scale operation, temperature variations could also be compensated for by varying the solvent flow rate in conjunction with an appropriate temperature management plan. 
Table 6. Stage Efficiency for Flowsheet Tests

\begin{tabular}{|c|c|c|}
\hline \multirow{2}{*}{ Test } & \multicolumn{2}{|c|}{ Stage Efficiency, \% } \\
\cline { 2 - 3 } & Extraction Section $^{\mathrm{a}}$ & Strip Section $^{\mathrm{a}}$ \\
\hline CS23 & $85 \pm 5^{\mathrm{b}}$ & $85 \pm 5$ \\
\hline CS24 & $89 \pm 3$ & $85 \pm 3$ \\
\hline CS25 & $88 \pm 3$ & $90 \pm 3$ \\
\hline
\end{tabular}

a. Determined before the concentration profile starts to flatten out.

b. This value is based on an activation energy of $-110 \mathrm{~kJ} / \mathrm{mol}$ for the effect of temperature on the cesium distribution ratio in the extraction section that best seems to fit the data. This activation energy must be used with care as the temperature during test CS23 was only measured for the feeds and effluents. No measurements were made of the contactor housing during test CS23 as was done during tests CS24 and CS25. Using recently published data from ORNL [BONNESEN-2000], we get an activation energy of $-63 \mathrm{~kJ} / \mathrm{mol}$. If this activation energy had been used, the apparent stage efficiency for the extraction section would have been $70 \pm 5 \%$.

\section{SUMMARY AND CONCLUSIONS}

The CSSX process to remove cesium from SRS high-level waste was tested in a minicontactor. First, the minicontactor was modified so that stage efficiency was improved from $60 \%$ to greater than $80 \%$. Multistage efficiency tests were done to show that the desired improvement had been achieved. Second, 8 stages were added to the existing 24-stage 2-cm contactor test facility. All stages were modified so that they operate at the improved efficiency. Third, the CSSX flowsheet was demonstrated in this 32-stage unit, first without solvent recycle, then with it. In both cases, the key process goals required by SRS were achieved: (1) the cesium was removed from the waste with decontamination factors greater than 40,000 and (2) the recovered cesium was concentrated by a factor of 15 in dilute nitric acid. Oak Ridge National Laboratory (ORNL) analysis of the recycled solvent showed no evidence of impurity buildup. This work completes the proof-of-concept of the CSSX process.

Based on the success of this test, further flowsheets will be done at ANL and SRS. These flowsheet tests will use the lessons learned in the proof-of-concept flowsheet tests. In the tests, the solvent will be recycled many times in order to see long-term process effects, especially the buildup of degradation products in the solvent. Argonne National Laboratory will do a five-day test with SRS simulant. Savannah River Site will do a three-day test with real waste from the SRS tanks. Both tests are planned in March 2001. 


\section{ACKNOWLEDGMENTS}

This work was supported by the Office of Environment Management of the U.S. Department of Energy through (1) the Office of Project Completion and (2) the Tank Focus Area of the Office of Science and Technology under Contract W-31-109-Eng-38 with Argonne National Laboratory, managed by the University of Chicago.

The authors wish to acknowledge the help of Greg Dolnak, ANL Waste Management Operations, in setting up and running the tests reported here and the help of Frank Markun, Del Bowers, and Lillian Ruscic, all of the ANL Chemical Technology Division, in preparing the test solutions. Tests CS23, CS24, and CS25 were observed by Reid Peterson and Paul Rutland, both of SRTC. Tests CS23 and CS24 were observed by Ken Rueter of SRTC. Tests CS23 and CS25 were observed by Joe Carter of SRTC. This report was reviewed by the following outside people: Ken Rueter, SRTC; Leon Klatt and Bruce Moyer, ORNL; and Patricia Suggs, DOE-SR.

\section{REFERENCES}

BONNESEN-2000

P. V. Bonnesen, L. H. Delmau, B. A. Moyer, and R. A. Leonard, "A Robust AlkalineSide CSEX Solvent Suitable for Removing Cesium from Savannah River High Level Waste," Sol. Extr. and Ion Exch. 18(6), 1079-1108 (2000).

LEONARD-1994

R. A. Leonard and M. C. Regalbuto, "A Spreadsheet Algorithm for Stagewise Solvent Extraction," Sol. Extr. and Ion Exch. 12(5), 909-930 (1994).

LEONARD-1999

R. A. Leonard, C. Conner, M. W. Liberatore, J. Sedlet, S. B. Aase, and G. F. Vandegrift, "Evaluation of an Alkaline-Side Solvent Extraction Process for Cesium Removal from SRS Tank Waste Using Laboratory-Scale Centrifugal Contactors," Argonne National Laboratory Report ANL-99/14 (1999).

\section{LEVENSON-2000}

M. Levenson, et al, "Alternatives for High-Level Waste Salt Processing at the Savannah River Site”, National Research Council, National Academy Press, Washington, DC (2000).

\section{LEONARD-2000}

R. A. Leonard, C. Conner, M. W. Liberatore, J. Sedlet, S. B. Aase, G. F. Vandegrift, L. H. Delmau, P. V. Bonnesen, and B. A. Moyer, "Development of a Solvent Extraction Process for Cesium Removal from SRS Tank Waste," to be published in Sep. Sci. Technol. 
PETERSON-2000

R. A. Peterson, "Preparation of Simulated Waste Solutions for Solvent Extraction Testing," Westinghouse Savannah River Co. Report WSRC-RP-2000-361 (May 1, 2000). 